\title{
Risk factors and management of post-liver transplant recurrence of hepatocellular carcinoma
}

\author{
Ashwin Rammohan, Mohamed Rela \\ The Institute of Liver Disease and Transplantation, Dr. Rela Institute and Medical Centre, Bharath Institute of Higher Education \\ and Research, Chennai 600044, India. \\ Correspondence to: Prof. Mohamed Rela, The Institute of Liver Disease and Transplantation, Dr. Rela Institute and Medical \\ Centre, Bharath Institute of Higher Education and Research, CLC Works Road, Chennai 600044, India. E-mail: \\ mohamed.rela@gmail.com
}

How to cite this article: Rammohan A, Rela M. Risk factors and management of post-liver transplant recurrence of hepatocellular carcinoma. Hepatoma Res 2021;7:49. https://dx.doi.org/10.20517/2394-5079.2020.160

Received: 14 Dec 2020 First Decision: 1 Feb 2021 Revised: 2 Feb 2021 Accepted: 19 Feb 2021 Published: 29 Jun 2021

Academic Editors: Geoff McCaughan, James Fung, Kenneth Siu Ho Chok Copy Editor: Xi-Jun Chen Production Editor: Xi-Jun Chen

\begin{abstract}
Hepatocellular carcinoma (HCC) is one of the most common indications for liver transplantation (LT). With expanding criteria and increasing number of transplants, post-transplant recurrence of $\mathrm{HCC}$ remains an important cause for concern and portends a poor survival in these patients. Traditionally, HCC recurrence post-LT has been notoriously difficult to manage and their outcomes dismal. A better understanding of the tumour biology and its interplay with the immune system, combined with newer oncological interventions has allowed for improved survivals in these patients. A useful classification of $\mathrm{HCC}$ recurrence is where it is divided into oligo-recurrence and disseminated recurrence. This system helps strategize their multi-disciplinary management algorithm and prognosticate outcomes. We provide an overview of the factors which may predict recurrence and summarise the current evidence on the management of post-LT HCC recurrence.
\end{abstract}

Keywords: Hepatocellular carcinoma, post-liver transplantation, recurrence, management

\section{INTRODUCTION}

Hepatocellular carcinoma (HCC) especially in a cirrhotic liver is best treated by liver transplantation (LT) for a myriad of reasons. Apart from providing the widest possible resection margin, LT also treats the underlying liver disease and removes the tumorigenic liver reducing the risk of recurrence. Nevertheless, 
despite stringent morphologic selection criteria like the Milan criteria (MC), recurrence is observed in 6\%$20 \%$ of patients transplanted for $\mathrm{HCC}^{[1-3]}$. Conventionally, post-LT tumour recurrence (TR) has been notoriously difficult to treat and has a universally poor prognosis. It is hence imperative that modifiable risk factors are elucidated. This will help improve patient selection and potentially reduce TR. With no strong consensus or large trials, literature with regards to its management is limited, and often anecdotal. The present narrative review summarizes the current available literature on the risk factors for TR and the management algorithm for HCC recurrence after LT.

\section{EPIDEMIOLOGY}

Despite expanding indications and better elucidation of tumour biology, the incidence of TR has remained remarkably constant over the past two decades at 10\%-20\%. As demonstrated in a systematic review which included 61 studies, the median time from LT to TR was 13 months (range: 2-132 months) with a recurrence rate of $16 \%{ }^{[4]}$. Even though TR as late as 10 years post-LT has been documented, TR is frequently observed in the first 2 post-LT years. TRs are most commonly observed extrahepatically (as high as 70\%); intrahepatic (within the liver graft) recurrence is a rarer phenomenon ${ }^{[1,2,5]}$. Although post-TR survival show improving trends in recent years, the median survival rates are still under 2 years ${ }^{[1-6]}$.

\section{RISK FACTORS FOR TUMOR RECURRENCE}

Before embarking on the management of post-LT HCC recurrence it is imperative to understand the interplay of tumour, patient, and treatment related factors which may be linked to the increased risk of TR in the post-LT setting.

\section{Tumour morphology, staging, vascular invasion}

The MC set the benchmark for size and number of nodules in predicting the risk of TR and survival in HCC patients undergoing $\mathrm{LT}^{[7]}$. However, it must be borne in mind that the size of the tumour correlate more closely with the risk of TR than the number ${ }^{[8-11]}$. A meta-analysis of 101 articles by Germani et al.$^{[9]}$ showed that the risk of TR had no association with the number of nodules, but was directly proportional to the diameter of the largest nodule. Another cohort study showed 36\% increase in the risk of TR for each centimetre increase in the diameter of the largest tumour nodule ${ }^{[11]}$. The reason postulated in the study was that the size of the tumour directly correlated with the risk of vascular invasion. Hence, size of the tumour is a higher risk factor for HCC recurrence than the number of tumours ${ }^{[3,8,9,1]}$. Several units have utilised this principle to expand on the MC, demonstrating similar survival figures with their "expanded" criteria. These principles have been succinctly summarised in the "metro-ticket model" for HCC ${ }^{[12]}$.

Macrovascular tumour invasion is considered a contraindication for LT and can be detected on pretransplant imaging ${ }^{[9-1,13]}$. Microvascular invasion $(\mathrm{mIV})$ on the other hand can only be identified on explant histopathology. The presence of mIV doubles the risk of death in patients with HCC; it is hence an important factor determining the risk of $\mathrm{TR}^{[3,9,10,13]}$. As also shown by Agopian et al. ${ }^{[14]}$ in their series of 865 patients who underwent LT for HCC, the risk of TR was increased by 2-7 times in the presence of vascular invasion. Staging systems act as a surrogate marker for mIV. Tumours within the MC (stage T2 HCC) and beyond MC (up to 7 criteria) were observed to have $16.6 \%$ and $50.2 \% \mathrm{mIV}$ respectively on explant histopathology $\mathrm{y}^{[3,8,12,14]}$.

\section{Degree of differentiation}

Differentiation of a tumour is an indication of its biology. On explant histopathology $11 \%-25 \%$ of tumours have been noted to be poorly differentiated ${ }^{[9,15,16]}$. This frequency increases with progressive expansion of the morphological selection criteria. A significantly higher risk of up to $40 \%$ TR has been observed when the 
tumour is poorly differentiated ${ }^{[16]}$. Unfortunately, due to its inherent bias, pre-LT tumour biopsy has a poor sensitivity $(29 \%)$ and positive predictive value $(35 \%)$ in identifying these sub-group of tumour; and is not recommended ${ }^{[17]}$.

\section{Circulating tumour cells and cell-free DNA}

The field of biomarkers is an area garnering a lot of interest. These markers are important when the tumour is a non-secretor with regards to conventional tumour markers like alpha-fetoprotein (AFP). Potentially a simple blood test can help in the diagnosis, prognostication, and management of TR, a modality termed as "liquid biopsy"[18-20]. Detecting circulating tumour cells (CTC) is one such tool which enables the assessment of treatment completeness. Epithelial cell adhesion molecule (EpCAM)-positive CTC in the peripheral blood have shown to demonstrate a significant association with advanced disease and shorter overall survival. A study from China which included 193 post-LT for HCC patients demonstrated that the presence of EpCAM-positive CTC was predictive of $\mathrm{TR}^{[21,22]}$. The significant finding in the study was that serial CTC monitoring detected TR even in tumour marker (AFP and PIVKA-II) negative patients. Another series from Germany showed that the positive predictive value of CTC detection for TR was $89 \%$, even when the TR was untraceable by current imaging techniques ${ }^{[23]}$. The study also showed that CTC could define the burden of micro-metastases and hence was also useful in prognosticating TR.

Circulating cell-free DNA (cfDNA) is a short fragment of double-stranded extracellular DNA that is released into the bloodstream by tumour apoptosis and/or dead cells, and is found in many types of cancers including $\mathrm{HCC}^{[24-28]}$. The development of next generation sequencing has allowed for this modality to mature into one of clinical importance. The levels of cfDNA drop back to normal when a tumour is completely removed. Hence, the levels of postoperative circulating cfDNA correlate with the presence of microscopic residual disease. Therefore, postoperative cfDNA helps identify the high-risk group for TR and has potential to be excellent monitoring tool for TR, especially when traditional methods of cannot provide evidence $^{[24-28]}$.

\section{Alpha-fetoprotein and response to loco-regional therapy}

Sixty percent of patients with HCC have elevated AFP levels. Very high AFP levels (> $1000 \mathrm{ng} / \mathrm{mL}$ ) are strongly associated with $\mathrm{mIV}$ and high TR $\left(47 \%\right.$ at 5 years ${ }^{[1,3,13,29]}$. Based on this statistic, certain centres exclude patients from the LT waitlist when the AFP levels are higher than $1000 \mathrm{ng} / \mathrm{mL}$. Interestingly, a very low AFP $(<16 \mathrm{ng} / \mathrm{mL})$ also predicts a poor post-LT survival ${ }^{[1,3,1,1,3,29]}$. A dramatic reduction in AFP following locoregional therapy (LRT) indicates an absence of extra-hepatic disease, and is a favourable prognostic indicator $^{[3,11]}$. Response to LRT is also a marker of the biological behaviour of the tumour ${ }^{[30-32]}$. As shown by Merani et al. ${ }^{[33]}$, even patients with an initial AFP above $1000 \mathrm{ng} / \mathrm{mL}$ could achieve a good outcome as long as their AFP dropped below $400 \mathrm{ng} / \mathrm{mL}$ with LRT. A systemic review and meta-analysis of studies over a 20year period showed that patients who were initially beyond MC (stage T3 HCC) and received LRT as downstaging therapy had a significantly higher 1-year and 5-year post-LT overall and disease-free survival (DFS) rates $^{[3,32]}$. Hence, LRT as downstaging or bridging therapy also plays a valuable role in prognostication.

\section{Neutrophil-lymphocyte ratio}

Neutrophil-lymphocyte ratio in the peripheral blood is a marker of inflammatory response. Aggressive tumours are noted to elicit a more exuberant inflammatory response; this phenomenon can be assessed using the neutrophil-lymphocyte ratio $^{[30-32]}$. It is utilised as an easily accessible tool to prognosticate tumours. Though not widely used, an elevated neutrophil-lymphocyte ratio (>5), as confirmed by a meta-analysis, has been associated with higher mIV and poorer survival ${ }^{[30-32]}$. 


\section{Aetiology}

Post-LT reactivation of hepatitis $\mathrm{B}$ virus (HBV) has shown a strong association with $\mathrm{TR}^{[30-32]}$. There is also a direct correlation of the HBV viral load and TR. Those with HBV viral load above 5 log have a 2.5 -fold risk of $\mathrm{TR}^{[30-32]}$. Interestingly the opposite is also true, studies have shown a very good temporal relationship between TR and HBV reactivation. TR is associated with an increased risk of HBV recurrence after LT, suggesting that HBV replication in tumour cells may contribute to this viral recurrence ${ }^{[34,35]}$. Data with regards to hepatitis $\mathrm{C}$ virus $(\mathrm{HCV})$ treatment with directly acting antiviral therapy (DAA) and TR has been mixed and needs long-term validation ${ }^{[36-39]}$. While the sustained virological response (SVR) rates have been very encouraging, the incidence of HCC in HCV patients has remained relatively constant ${ }^{[40-42]}$. Literature is divided with regards to SVR achieved by DAA and their effect of TR. In the CUPILT cohort, of 313 patients, only $2.2 \%$ who achieved SVR had $\mathrm{TR}^{[37]}$. While a smaller series showed a higher $\mathrm{TR}(28 \%)$ in patients treated pre-LT with DAAs ${ }^{[36]}$. Another study from Milan further muddied the waters by showing no significant difference in TR among patients treated pre-LT with DAAs ${ }^{[22]}$.

Up to a quarter of patients undergoing LT for HCC are obese. Obese patients tend to have a higher frequency of $\mathrm{mIV}$ and consequently a higher risk of $\mathrm{TR}^{[3,43]}$. This could be due to an increased expression of vascular endothelial growth factor (VEGF) from their adipose tissue which stimulates angiogenesis. Contrary to this, HCC in non-alcoholic fatty liver disease patients have a more indolent behaviour. Studies including those analysing the UNOS database have shown a $32 \%-80 \%$ lower rate of high-risk characteristic of $\mathrm{TR}^{[3,44,45]}$.

\section{Time to LT and bridging therapy}

Time to LT plays a significant part in the outcome. A waiting period enables an assessment of tumour biology ${ }^{[46]}$. On the other hand, allowing too long a waiting period will lead to tumour progression and a poorer outcome. A multicentre study from North America noted that patients had a significantly higher risk of TR if transplanted before 6 months or after 18 months of diagnosis of $\mathrm{HCC}^{[47]}$. During this waiting period rigorous follow-up is indicated along with bridging therapy to prevent dropouts. A favourable response to bridging therapy in the form of complete necrosis has been associated with a lower risk of $\mathrm{TR}^{[48-50]}$. A partial necrosis on the other hand, is associated with a higher risk of lymph node metastases and consequently a higher $\mathrm{TR}^{[48,49]}$.

\section{Donor age}

Evidence in this regards points to a higher risk of TR when older liver grafts are used in the LT. This has been linked to increased preservation injury and susceptibility to cold ischemia ${ }^{[51]}$. Liver grafts from donors older than 60 years of age have been linked to a $70 \%$ higher risk of TR than those patients who received younger liver grafts ${ }^{[52]}$.

\section{Ischemia time and ischemic/reperfusion injury}

Ischemia-reperfusion injury incites an inflammatory reaction which can accelerate tumour growth and promote micrometastases. A significantly higher risk of TR has been observed when the cold and warm ischemia times are over $10 \mathrm{~h}$ and 50 min respectively ${ }^{[3,51,53]}$.

\section{Surgical technique}

Minimal manipulation of the tumour-bearing liver during explant hepatectomy remains a crucial aspect of the operation ${ }^{[54,55]}$. Breach or spillage can lead to dissemination of tumour cells. The piggyback technique of $\mathrm{LT}$ involves preserving the native inferior vena cava. This technique could potentially involve a more vigorous manipulation of the liver while mobilising the liver off the inferior vena cava. There are reports of a "no-touch" modification to the explant hepatectomy in living donor LT (LDLT) which enable a complete 
hepatectomy without manipulating the tumour-bearing liver ${ }^{[5,57]}$. Herein, a veno-venous bypass is created, and the native inferior vena cava is excised and replaced with a prosthetic graft. Literature evidence is sparse in this regard, and a study by Mangus et al. ${ }^{[54]}$ found no difference in the rates of TR irrespective of the technique of outflow reconstruction ${ }^{[1,3,55]}$. Early studies including a meta-analysis comparing LDLT and deceased donor LT (DDLT) for HCC reported 60\% greater DFS in patients who underwent DDLT than those who underwent $\operatorname{LDLT}^{[3,13,58,59]}$. The possible explanations for poorer outcomes in the LDLT arm included a shorter waiting time to LT, which did not allow for an assessment of the tumour biology and identification of more aggressive tumours. Another reason suggested was the greater surgical manipulation in LDLT which could potentially contribute to the spread of neoplastic cells. Finally, it was suggested that rapid liver graft regeneration along with release of growth factor and cytokines could promote tumour growth and lead to TR. However, more recent and larger series including those from the A2ALL cohort have shown similar TR and DFS for LDLT and DDLT and that the previously presented results were skewed due to a staging bias ${ }^{[1,358-62]}$.

\section{Immunosuppression}

It has indubitably been shown that the native immune system is a key player in cancer control and that a subdued immune defence combined with tumour induced inflammation are responsible for $\mathrm{TR}^{[2-4,63]}$. A 2.8 fold higher risk of TR has been observed in patients who had high calcineurin inhibitor (CNI), specifically tacrolimus levels (above $10 \mathrm{ng} / \mathrm{mL}$ ) in the first month post- $\mathrm{LT}^{[1,3,64,65]} \cdot \mathrm{mTOR}$ inhibitors are a class of immunosuppressants which inhibit angiogenesis and cell proliferation. This purported anti-tumour effect is a property which is being explored to expand its applicability in transplant oncology two meta-analyses of 5 and 42 studies respectively noted a significantly lower risk of TR when mTOR inhibitors were used as immunosuppressants in conjunction with $\mathrm{CNIs} s^{[6,67]}$. The multicentre randomised SILVER trial aimed at assessing the efficacy of mTOR inhibitors (sirolimus) in LT for HCC. The mTOR inhibitor group had a 50\% lower risk of TR at one year and a higher DFS at 4 years post $\mathrm{LT}^{[68]}$. This benefit was observed in the younger population and in tumours within MC. There was also a gain of 6.4 months of DFS in the mTOR inhibitor group. The role of other immunosuppressants like antimetabolites, corticosteroids, or monoclonal antibodies have not been adequately assessed to make for a meaningful conclusion ${ }^{[3,5,13,63]}$. Nonetheless, reports suggest a generally increased risk of post-LT malignancy with their use. To summarise, minimising immunosuppression is a prudent approach. A higher dose of CNIs, especially in early post-LT period is associated with a higher risk of TR, while mTOR inhibitors reduce the risk of TR.

\section{POST-LT SURVEILLANCE}

There is no firm consensus on the protocol, frequency or duration of monitoring TR after $\operatorname{LT}^{[50,69,70]}$. Most centres follow a similar protocol of thoraco-abdominal CT and AFP levels at 3-to 6-months intervals during the first 2 or 3 years. The interval between the tests is increased after 2 years. A bone scintigraphy and/or PET Scan is reserved for patients who present with symptoms or suspicion of TR. In an attempt to stratify the risk of TR, studies have proposed objective scoring systems on the basis of AFP, histopathological characteristics like mIV, and tumour morphology ${ }^{[6,71,72]}$. These have, however, not found widespread acceptance and remain sporadically used.

\section{STAGING}

TR is essentially a metastatic disease and its management can only be guided by a comprehensive staging process; the essence of which is to delineate the extent of disease. PET-CT scans help in functional and anatomical assessment of the disease burden. Two radio isotopes are routinely used for $\mathrm{HCC}^{[73,7]}$. C11acetate PET better defines well-differentiated HCC, while the more unfavourable biology tumours tend to be FDG avid. PET-CT are very sensitive in picking up bone metastases ${ }^{[75,76]}$. When PET-CT is unavailable, a 
contrast CT should be combined with Tc-bone scan to complete a skeletal survey ${ }^{[2,4,70]}$.

\section{MANAGEMENT OF TR}

The patient should be jointly managed by the transplant surgeon, physician, oncologist, and radiologist as a multidisciplinary approach.

\section{Immunosuppression}

Irrespective of the type of recurrence, type and dose of immunosuppression should be titrated. The aim is to allow the body's immune system to act against the tumour, while protecting the graft from rejection. Although it is intuitive to reduce CNIs to a sub-therapeutic level, there are no recommendations on the optimum levels which should be maintained in this scenario ${ }^{[2,63,68,69]}$. Apart from an active dose reduction and immune-modulation, a switch in the immunosuppressants should also be considered. As described previously, while the data on reducing TR is relatively robust for mTOR inhibitors, there is sparse literature on their role in treatment of established TR after $\mathrm{LT}^{[66-68]}$. mTOR inhibitors as monotherapy are poor immunosuppressants and have a higher risk of rejection. It is, therefore, a common practice to incorporate an mTOR inhibitor with a low dose CNI upon the diagnosis of TR. Overall, immunosuppression should be individualized and tapered to permit an anti-tumour immune response.

\section{Oligo-recurrence}

Historically, all post-LT TR were considered terminal events, and were managed with palliation. Classification of recurrence into two categories has allowed for a better definition, delineation of extent of disease, management, and prognostication of the disease load. Broadly, TR can be classified into oligorecurrence (OR) and disseminated recurrence (DR). The term OR was first introduced in 1995 to described TR that was amenable to surgery or LRT with an aim to achieve either Ro resection or tumour control ${ }^{[77,78]}$. This classification led to a conceptual shift from a palliative intent to one of cure ${ }^{[1,2,6,77,78]}$. An objective definition for OR by size, number, or location has not been proposed and may be impractical due to the heterogeneity of TR. Instead, it provides a conceptual viewpoint in the management of TR with a limited tumour burden.

\section{Extra-hepatic oligo-recurrence}

Extra-hepatic TR constitute over $70 \%$ of the recurrences ${ }^{[2,45]}$. They are most commonly seen in the lungs followed by the bones. A series from Korea showed a significantly higher 5 -year survival rate (44.7\%vs. $12.8 \%$ ) when pulmonary OR (defined in the study as up to 3 tumours) were resected ${ }^{[79]}$. Residual pulmonary reserve and function remained an important consideration in such resections ${ }^{[2,70,79,80]}$. Stereotactic body radiotherapy (SBRT) is an option for patients where inadequate lung function precludes resection. Experience from a European multicentre series of 637 patients treated with SBRT showed that in well selected candidates the 3-year overall survival was $39.2 \%$. SBRT has also been successfully used to treat OR in the bones (local control of $79 \%-88 \%)^{[6,81,82]}$. Orthopaedic stabilisation of the affected bone may be needed before or during the course of SBRT to avoid pathological fractures. TR can also occur in the lymph nodes. This when picked up on imaging can be resected in the form of a formal lymph node dissection and clearance. Other extrahepatic sites include the adrenal glands. Options include a surgical excision of the recurrence. Trans-arterial chemoembolization (TACE) has also been shown to be effective in the managing adrenal metastases of $\mathrm{HCC}^{[83-85]}$. Achieving Ro margins has been shown to provide a survival benefit and hence, when feasible, resection should be offered for $\mathrm{OR}^{[1,2,6,69]}$.

\section{Hepatic oligo-recurrence}

TR in the liver graft should be differentiated from post-LT de novo HCC. Most TR occur early (within 2 years) in the post-LT period, and the characteristics are likely to be similar to that of the primary disease. 
On the other hand, de novo HCC occur years after LT, and more so in a diseased liver-graft (fibrosis, cirrhosis, chronic rejection, etc.). The key consideration between the two lies in its prognostication, de novo HCC are more likely to be limited to the liver, and hence amenable to cure when detected early ${ }^{[86]}$.

\section{Surgery}

Resection for liver based OR has been shown to be beneficial. Consideration for surgery may vary depending on the unit's policy and hinges on the tumour burden, location, and post-resection functional liver remnant. Since TR is usually early, liver function itself may not preclude surgery. Several series have shown increased median survival with surgery as compared to systemic therapy (28-65 months vs. 5-15 months) $)^{[2,4-6,87,88]}$. It must however be acknowledged that only $25 \%-50 \%$ of patients with OR eventually undergo an operation. This could lead to a selection bias, and the true benefit of surgery may never be elucidated. The presence of adhesions in the hepatic hilum and immunosuppression may explain the higher early postoperative morbidity. Nonetheless, long term survival (up to 70\% 3-year survival) has been demonstrated with Ro resection and should be considered when practicable $e^{[2,4-6,87,88]}$.

\section{Radiofrequency ablation/microwave ablation}

Concerns of surgical morbidity have prompted an increasing interest in other LRTs like radiofrequency ablation (RFA) and microwave ablation (MWA). However, unfavourable tumour location (proximity to other viscera and blood vessels, superficial lesions, etc.) and tumour burden are limiting factors in its application. Survival benefit has been demonstrated for small lesions $(<3 \mathrm{~cm}$ in size); the evidence however, is sparse in this regard ${ }^{[2,4,89]}$.

\section{Trans-arterial chemoembolization}

As compared to RFA, TACE allows for a wider area of regional control ${ }^{[00,91]}$. When anatomically localised, limitations of tumour burden may not apply in this case. Three-year survival of 6\%-48\% has been achieved with TACE, and disease progression or breakthrough is usually observed in the form of extra-hepatic disease $^{[92-96]}$. Due to concerns of biliary ischemia related complications, the role of TACE has remained undefined for TR. There are, however, reports of TR control with this modality ${ }^{[94-96]}$.

\section{Trans-arterial radioembolization}

Intra-parenchymal administration of Yttrium-90 microspheres enables a higher intensity to be localised onto the tumour bearing liver. Despite issues like cost and availability, trans-arterial radioembolization (TARE) has gained acceptance in the management of unresectable HCC. The main reason being that tumour or bland portal vein thrombus, is not a contraindication for its application ${ }^{[92,93]}$. Isolated reports have demonstrated a good response in the management of $\mathrm{TR}^{[94-97]}$.

\section{Stereotactic body radiation therapy}

Stereotactic body radiation therapy (SBRT) allows for a focused external beam of RT to ablate the tumour while sparing the adjacent liver. In addition to minimising damage to the normal liver, SBRT also stimulates the immunity and has shown to work synergistically with systemic therapy which modulate the immune system (e.g., anti-PD1 therapy) ${ }^{[2,4,98]}$. Apart from anecdotal reports of its efficacy in TR, there are no formal studies in this regard. Moreover, the role of immunotherapy is highly controversial in the post-LT setting (discussed below).

\section{Disseminated recurrence}

When the TR is disseminated and not amenable to LRT, the management changes from an intention to cure to one of prolonging survival. 


\section{Chemotherapy}

HCCs are notoriously chemo-resistant tumours, and chemotherapy has limited role in its management. Several small series analysing the role of chemotherapy in TR post-LT have shown no objective response ${ }^{[1,2,4,94,99-101]}$. Numerous chemotherapeutic agents have been used, and this heterogeneity attests to the fact that no one particular regimen is effective. Adverse effect profile in these patients remain another limiting factor in the use of chemotherapeutic agents. A meta-analysis found up to $86 \%$ incidence of adverse effects when adjuvant chemotherapy was used in the post-LT setting ${ }^{[94]}$. The meta-analysis also noted that there was no evidence to demonstrate whether the use of chemotherapy affected TR rates.

\section{Targeted therapy}

Sorafenib is a multi-kinase inhibitor proven to have anti-HCC action. The SHARP trial was the first of its kind to show that sorafenib provided a 3-month survival advantage in patients with advanced HCC $^{[102]}$. Interestingly, in mice, Sorafenib and mTOR inhibitors have a synergistic effect on inhibiting tumour growth. A study of 15 patients showed a similar survival advantage when the two drugs were combined ${ }^{[101,103,104]}$. This, however, came at the expense of higher drug toxicity and bleeding complications.

The RESORCE trial was a phase 3 multicentre randomized controlled trial which showed regorafenib to improve survival in patients with advanced HCC which had progressed despite sorafenib therapy ${ }^{[105-108]}$. It is noteworthy that post-LT TR was an exclusion criterion for the study, as it was in all other phase III studies on systemic therapies. The only study to date to evaluate the role of systemic sorafenib-regorafenib in TR was a retrospective, observational, multicentre, international study involving 14 centres across Europe and Argentina ${ }^{[109]}$. Despite a near universal occurrence of adverse events, the trial showed a median survival after regorafenib therapy and sorafenib-regorafenib sequential treatment to be 12.9 months and 38.4 months, respectively. Nonetheless, the median time to recurrence in the study was 26.4 months, indicating a bias towards selecting outpatients with a better prognosis. An interesting finding noted in the study was that regorafenib which is a competitive inhibitor of cytochromes led to a significant increase in the levels of CNIs and mTOR inhibitors.

Lenvatinib is a tyrosine kinase inhibitor which blocks VEGF as well as fibroblast growth factor (FGF) and platelet derived growth factor (PDGF) pathways. In the non-LT population, a phase 3 randomised control trial (REFLECT trial) showed non-inferior survival with lenvatinib vs. sorafenib (13.6 months vs. 12.3 months $)^{[110-112]}$. The adverse event profile was, however, more severe in the lenvatinib arm. Again, there is no strong data regarding lenvatinib in TR. Anecdotal reports demonstrated an extended time to tumour recurrence when lenvatinib was used as systemic therapy for TR. The patient in an Argentinian case report had over 15 months of disease progression-free survival ${ }^{[113]}$. Although in that report, the authors conceded that there was lack of clarity on the real benefit of lenvatinib on TR survival. Nonetheless, trials (ClinicalTrials.gov Identifier: NCT04168944) are underway to elucidate its role in $\mathrm{TR}^{[114]}$.

Cabozantinib inhibits tyrosine kinases, including VEGF receptors 1, 2, and 3, MET, AXL, and the angiopoietin receptors TIE-2, RET, c-Kit, and FLT-3, which are implicated in the progression of HCC and the development of resistance to sorafenib ${ }^{[115-117]}$. The CELESTIAL trial was a randomized, double-blind, phase 3 trial which evaluated cabozantinib as compared with placebo in previously treated patients with advanced $\mathrm{HCC}^{[115]}$. Here again LT recipients were excluded from the study. The trials showed an additional 2 months' survival benefit as compared to the placebo group. The drug is however not cost effective and is associated with high-grade adverse events. There hence remains a paucity of data on utilizing cabozantinib as the second-line agent ${ }^{[116,117]}$. Trials including a phase 2 trial (ClinicalTrials.gov Identifier: NCT04204850) assessing the role of cabozantinib in TR are underway, and are likely to complete accruing patients in the next couple of years ${ }^{[118]}$. Data in the post-LT population could potentially help cabozantinib be part of the 
systemic therapy algorithm of TR.

\section{Immunotherapy}

HCCs are a heterogeneous group of tumours driven by inflammation, and hence the rationale to evaluate immunotherapy ${ }^{[119-121]}$. The immune response is regulated by immune checkpoints. Inhibiting these checkpoints prompt the native immune system to react against the tumour antigen ${ }^{[119,122]}$. One such immune checkpoint protein is the programmed death receptor $1(\mathrm{PD}-1)^{[123]}$. It is an inhibitory molecule expressed on the surface of multiple tissue types and keeps the T cells from attacking tumour cells. Pembrolizumab and nivolumab are monoclonal immunoglobulins against PD-1 that block the signalling of PD- $1^{[119,122]}$. Encouraging results have been demonstrated in patients with advanced HCC who previously failed sorafenib treatment ${ }^{[124-127]}$. Their role however in the post-LT remains undefined, especially since boosting the immune system is likely to increase the risk of rejection ${ }^{[128-130]}$. Case reports and small series of post-LT patients with TR treated anti-PD1 agents have shown a higher incidence of rejection and graft loss. There have, however, been instances where a total remission of TR has been observed ${ }^{[124,125]}$. Based on these reports, it can be deduced that younger patients in the early post-LT period on an aggressive immunosuppression regimen were at a significantly higher risk of losing their liver graft. Another molecule which follows a different pathway to modulate the immune system is the CTLA-4. Blockade of CTLA-4 by Ipilimumab may in theory allow for anti-tumour response without affecting graft tolerance ${ }^{[119,121,122]}$. It can hence be concluded that the place of immunotherapy in managing post-LT TR remains to be defined. Their anti-tumour benefit needs to be balanced against the risk of graft rejection and loss. Further studies in large patient cohorts will help elucidate this conundrum.

\section{CONCLUSION}

There is paucity of high-level evidence and a limited experience in the management of post-LT TR. A multidisciplinary management provides the best possible outcome for these patients who would otherwise have a dismal outcome. Striking a fine balance between tapering immunosuppression to allow for the native immune action against HCC while protecting against rejection is the first step in the management of these patients. Stratifying TR into oligo- or disseminated recurrence enables better prognostication and application of more aggressive therapeutic strategies in selected patients.

\section{DECLARATIONS}

\section{Authors' contributions}

Made substantial contributions to conception and design of the study and performed data analysis and interpretation: Rammohan A, Rela M

Performed data acquisition, as well as provided administrative, technical, and material support: Rammohan

A, Rela M

Final approval of the article: Rela M

\section{Availability of data and materials}

Not applicable.

\section{Financial support and sponsorship}

None.

\section{Conflicts of interest}

Both authors declared that there are no conflicts of interest. 


\section{Ethical approval and consent to participate}

Not applicable.

\section{Consent for publication}

Not applicable.

\section{Copyright}

(c) The Author(s) 2021.

\section{REFERENCES}

1. Nagai S, Mangus RS, Kubal CA, et al. Prognosis after recurrence of hepatocellular carcinoma in liver transplantation: predictors for successful treatment and survival. Clin Transplant 2015;29:1156-63. DOI PubMed

2. Au KP, Ho Chok KS. Multidisciplinary approach for post-liver transplant recurrence of hepatocellular carcinoma: A proposed management algorithm. World J Gastroenterol 2018;24:5081-94. DOI PubMed PMC

3. Filgueira NA. Hepatocellular carcinoma recurrence after liver transplantation: Risk factors, screening and clinical presentation. World J Hepatol 2019;11:261-72. DOI PubMed PMC

4. De'Angelis N, Landi F, Carra MC, Azoulay D. Managements of recurrent hepatocellular carcinoma after liver transplantation: a systematic review. World J Gastroenterol 2015;21:11185-98. DOI PubMed PMC

5. Pfiffer TEF, Seehofer D, Nicolaou A, Neuhaus R, Riess H, Trappe RU. Recurrent hepatocellular carcinoma in liver transplant recipients: parameters affecting time to recurrence, treatment options and survival in the sorafenib era. Tumori 2011;97:436-41. DOI PubMed

6. Sapisochin G, Goldaracena N, Astete S, et al. Benefit of treating hepatocellular carcinoma recurrence after liver transplantation and analysis of prognostic factors for survival in a Large Euro-American Series. Ann Surg Oncol 2015;22:2286-94. DOI PubMed

7. Mazzaferro V, Regalia E, Doci R, et al. Liver transplantation for the treatment of small hepatocellular carcinomas in patients with cirrhosis. N Engl J Med 1996;334:693-9. DOI PubMed

8. Mazzaferro V, Bhoori S, Sposito C, et al. Milan criteria in liver transplantation for hepatocellular carcinoma: An evidence-based analysis of 15 years of experience. Liver Transpl 2011;17 Suppl 2:S44-57. DOI PubMed

9. Germani G, Gurusamy K, Garcovich M, et al. Which matters most: number of tumors, size of the largest tumor, or total tumor volume? Liver Transpl 2011;17 Suppl 2:S58-66. DOI PubMed

10. Mazzaferro V, Llovet JM, Miceli R, et al. Predicting survival after liver transplantation in patients with hepatocellular carcinoma beyond the Milan criteria: a retrospective, exploratory analysis. Lancet Oncol 2009;10:35-43. DOI PubMed

11. Welling TH, Eddinger K, Carrier K, et al. Multicenter study of staging and therapeutic predictors of hepatocellular carcinoma recurrence following transplantation. Liver Transpl 2018;24:1233-42. DOI PubMed PMC

12. Mazzaferro V, Sposito C, Zhou J, et al. Metroticket 2.0 model for analysis of competing risks of death after liver transplantation for hepatocellular carcinoma. Gastroenterology 2018;154:128-39. DOI PubMed

13. Nagai S, Mangus RS, Kubal CA, et al. Prognosis after recurrence of hepatocellular carcinoma in liver transplantation: Predictors for successful treatment and survival. Clin Transplant 2015;29:1156-63. DOI PubMed

14. Agopian VG, Harlander-Locke M, Zarrinpar A, et al. A novel prognostic nomogram accurately predicts hepatocellular carcinoma recurrence after liver transplantation: Analysis of 865 consecutive liver transplant recipients. J Am Coll Surg 2015;220:416-27. DOI PubMed

15. Yao FY, Ferrell L, Bass NM, et al. Liver transplantation for hepatocellular carcinoma: expansion of the tumor size limits does not adversely impact survival. Hepatology 2001;33:1394-403. DOI

16. Donat M, Alonso S, Pereira F, et al. Impact of histological factors of hepatocellular carcinoma on the outcome of liver transplantation. Transplant Proc 2016;48:1968-77. DOI PubMed

17. Court CM, Harlander-Locke MP, Markovic D, et al. Determination of hepatocellular carcinoma grade by needle biopsy is unreliable for liver transplant candidate selection. Liver Transplant 2017;23:1123-32. DOI PubMed

18. Palmirotta R, Lovero D, Cafforio P, et al. Liquid biopsy of cancer: a multimodal diagnostic tool in clinical oncology. Ther Adv Med Oncol 2018;10:1758835918794630. DOI PubMed PMC

19. Llovet JM, Montal R, Sia D, Finn RS. Molecular therapies and precision medicine for hepatocellular carcinoma. Nat Rev Clin Oncol 2018;15:599-616. DOI PubMed

20. von Felden J, Schulze K, Krech T, et al. Circulating tumor cells as liquid biomarker for high HCC recurrence risk after curative liver resection. Oncotarget 2017;8:89978-87. DOI PubMed PMC

21. Wang P, Xu Y, Sun Y, et al. Detection of circulating tumour cells enables early recurrence prediction in hepatocellular carcinoma patients undergoing liver transplantation. Liver Int 2021;41:562-73. DOI PubMed

22. Sun YF, Xu Y, Yang XR, et al. Circulating stem cell-like epithelial cell adhesion molecule-positive tumor cells indicate poor prognosis of hepatocellular carcinoma after curative resection. Hepatology 2013;57:1458-68. DOI PubMed

23. Schulze K, Gasch C, Staufer K, et al. Presence of EpCAM-positive circulating tumor cells as biomarker for systemic disease strongly correlates to survival in patients with hepatocellular carcinoma. Int J Cancer 2013;133:2165-71. DOI PubMed

24. Long G, Fang T, Su W, Mi X, Zhou L. The prognostic value of postoperative circulating cell-free DNA in operable hepatocellular 
carcinoma. Scand J Gastroenterol 2020;55:1441-6. DOI PubMed

25. Wang D, Hu X, Long G, Xiao L, Wang ZM, Zhou LD. The clinical value of total plasma cell-free DNA in hepatitis B virus-related hepatocellular carcinoma. Ann Transl Med 2019;7:650. DOI PubMed PMC

26. Yan L, Chen Y, Zhou J, Zhao H, Zhang H, Wang G. Diagnostic value of circulating cell-free DNA levels for hepatocellular carcinoma. Int J Infect Dis 2018;67:92-7. DOI PubMed

27. Mezzalira S, De Mattia E, Guardascione M, Dalle Fratte C, Cecchin E, Toffoli G. Circulating-free DNA analysis in hepatocellular carcinoma: a promising strategy to improve patients' management and therapy outcomes. Int J Mol Sci 2019;20:5498. DOI PubMed PMC

28. Alunni-Fabbroni M, Rönsch K, Huber T, et al. Circulating DNA as prognostic biomarker in patients with advanced hepatocellular carcinoma: A translational exploratory study from the SORAMIC trial. J Transl Med 2019;17:328. DOI PubMed PMC

29. Hameed B, Mehta N, Sapisochin G, Roberts JP, Yao FY. Alpha-fetoprotein level $>1000 \mathrm{ng} / \mathrm{mL}$ as an exclusion criterion for liver transplantation in patients with hepatocellular carcinoma meeting the Milan criteria. Liver Transpl 2014;20:945-51. DOI PubMed PMC

30. Wu TH, Wang YC, Cheng CH, et al. Outcomes associated with the intention of loco-regional therapy prior to living donor liver transplantation for hepatocellular carcinoma. World J Gastrointest Surg 2020;12:17-27. DOI PubMed PMC

31. Grąt M, Krawczyk M, Stypułkowski J, et al. Prognostic relevance of a complete pathologic response in liver transplantation for hepatocellular carcinoma. Ann Surg Oncol 2019;26:4556-65. DOI PubMed PMC

32. Pompili M, Francica G, Ponziani FR, Iezzi R, Avolio AW. Bridging and downstaging treatments for hepatocellular carcinoma in patients on the waiting list for liver transplantation. World J Gastroenterol 2013;19:7515-30. DOI PubMed PMC

33. Merani S, Majno P, Kneteman NM, et al. The impact of waiting list alpha-fetoprotein changes on the outcome of liver transplant for hepatocellular carcinoma. J Hepatol 2011;55:814-9. DOI PubMed

34. Fung J, Wong DK, Tanaka Y, et al. Quantitative hepatitis B surface antigen in predicting recurrence of hepatitis B-related hepatocellular carcinoma after liver transplantation. Hepatoma Res 2018;4:62. DOI

35. Faria LC, Gigou M, Roque-Afonso AM, et al. Hepatocellular carcinoma is associated with an increased risk of hepatitis B virus recurrence after liver transplantation. Gastroenterology 2008;134:1890-9. DOI PubMed

36. Nahon P, Layese R, Bourcier V, et al; ANRS CO12 CirVir Group. Incidence of hepatocellular carcinoma after direct antiviral therapy for hcv in patients with cirrhosis included in surveillance programs. Gastroenterology 2018;155:1436-50.e6. DOI PubMed

37. ANRS collaborative study group on hepatocellular carcinoma (ANRS CO22 HEPATHER, CO12 CirVir and CO23 CUPILT cohorts). Lack of evidence of an effect of direct-acting antivirals on the recurrence of hepatocellular carcinoma: data from three ANRS cohorts. J Hepatol 2016;65:734-40. DOI

38. Kolly P, Dufour JF. A strong message is needed to address the issue of HCC recurrence after DAA therapy. J Hepatol 2016;65:12689. DOI PubMed

39. Kohli V, Singhal A, Elliott L, Jalil S. Antiviral therapy for recurrent hepatitis C reduces recurrence of hepatocellular carcinoma following liver transplantation. Transpl Int 2012;25:192-200. DOI PubMed

40. Bozorgzadeh A, Orloff M, Abt P, et al. Survival outcomes in liver transplantation for hepatocellular carcinoma, comparing impact of hepatitis C versus other etiology of cirrhosis. Liver Transpl 2007;13:807-13. DOI PubMed

41. Vidal RIO, Vidal EIO, Pereira BB, et al. Risk factors for hepatocellular carcinoma recurrence and survival after liver transplantation in patients with hcv-related cirrhosis. Biomed Res Int 2020;2020:1487593. DOI PubMed PMC

42. Zanetto A, Shalaby S, Vitale A, et al. Dropout rate from the liver transplant waiting list because of hepatocellular carcinoma progression in hepatitis C virus-infected patients treated with direct-acting antivirals. Liver Transplant 2017;23:1103-12. DOI PubMed

43. Siegel AB, Lim EA, Wang S, et al. Diabetes, body mass index, and outcomes in hepatocellular carcinoma patients undergoing liver transplantation. Transplantation 2012;94:539-43. DOI PubMed PMC

44. Sadler EM, Mehta N, Bhat M, et al. Liver transplantation for NASH-related hepatocellular carcinoma versus Non-NASH etiologies of hepatocellular carcinoma. Transplantation 2018;102:640-7. DOI PubMed

45. Lewin SM, Mehta N, Kelley RK, Roberts JP, Yao FY, Brandman D. Liver transplantation recipients with nonalcoholic steatohepatitis have lower risk hepatocellular carcinoma. Liver Transplant 2017;23:1015-22. DOI PubMed

46. Schlansky B, Chen Y, Scott DL, Austin D, Naugler WE. Waiting time predicts survival after liver transplantation for hepatocellular carcinoma: a cohort study using the United Network for Organ Sharing registry. Liver Transpl 2014;20:1045-56. DOI PubMed

47. Mehta N, Heimbach J, Lee D, et al. Wait time of less than 6 and greater than 18 months predicts hepatocellular carcinoma recurrence after liver transplantation: proposing a wait time "sweet Spot". Transplantation 2017;101:2071-8. DOI PubMed PMC

48. Agopian VG, Harlander-Locke MP, Ruiz RM, et al. Impact of pretransplant bridging locoregional therapy for patients with hepatocellular carcinoma within Milan criteria undergoing liver transplantation: analysis of 3601 patients from the US Multicenter HCC Transplant Consortium. Ann Surg 2017;266:525-35. DOI PubMed

49. Xu M, Doyle MM, Banan B, et al. Neoadjuvant locoregional therapy and recurrent hepatocellular carcinoma after liver transplantation. J Am Coll Surg 2017;225:28-40. DOI PubMed PMC

50. Clavien PA, Lesurtel M, Bossuyt PMM, Gores GJ, Langer B, Perrier A; OLT for HCC Consensus Group. Recommendations for liver transplantation for hepatocellular carcinoma: An international consensus conference report. Lancet Oncol 2012:13e11-22. DOI PubMed PMC

51. Nagai S, Yoshida A, Facciuto M, et al. Ischemia time impacts recurrence of hepatocellular carcinoma after liver transplantation. Hepatology 2015;61:895-904. DOI PubMed 
52. Vagefi PA, Dodge JL, Yao FY, Roberts JP. Potential role of the donor in hepatocellular carcinoma recurrence after liver transplantation. Liver Transpl 2015;21:187-94. DOI PubMed PMC

53. Kornberg A, Witt U, Kornberg J, Friess H, Thrum K. Extended ischemia times promote risk of HCC recurrence in liver transplant patients. Dig Dis Sci 2015;60:2832-9. DOI PubMed

54. Mangus RS, Fridell JA, Vianna RM, Cooper AB, Jones DT, Tector AJ. Use of the piggyback hepatectomy technique in liver transplant recipients with hepatocellular carcinoma. Transplantation 2008;85:1496-9. DOI PubMed

55. Grat M, Kornasiewicz O, Lewandowski Z, et al. The impact of surgical technique on the results of liver transplantation in patients with hepatocellular carcinoma. Ann Transplant 2013;18:448-59. DOI PubMed

56. Moon DB, Lee SG, Hwang S, et al. No-touch en bloc right lobe living-donor liver transplantation with inferior vena cava replacement for hepatocellular carcinoma close to retrohepatic inferior vena cava: case report. Transplant Proc 2013;45:3135-9. DOI PubMed

57. Matsuda H, Sadamori H, Shinoura S, et al. Aggressive combined resection of hepatic inferior vena cava, with replacement by a ringed expanded polytetrafluoroethylene graft, in living-donor liver transplantation for hepatocellular carcinoma beyond the Milan criteria. J Hepatobiliary Pancreat Sci 2010;17:719-24. DOI PubMed

58. Kulik LM, Fisher RA, Rodrigo DR, et al. Outcomes of living and deceased donor liver transplant recipients with hepatocellular carcinoma: results of the A2ALL cohort. Am J Transplant 2012;12:2997-3007. DOI PubMed PMC

59. Grant RC, Sandhu L, Dixon PR, Greig PD, Grant DR, Mcgilvray ID. Living vs. deceased donor liver transplantation for hepatocellular carcinoma: A systematic review and meta-analysis. Clin Transplant 2013;27:140-7. DOI PubMed

60. Wong TCL, Ng KKC, Fung JYY, et al. Long-term survival outcome between living donor and deceased donor liver transplant for hepatocellular carcinoma: intention-to-treat and propensity score matching analyses. Ann Surg Oncol 2019;26:1454-62. DOI PubMed

61. Xiao GQ, Song JL, Shen S, Yang JY, Yan LN. Living donor liver transplantation does not increase tumor recurrence of hepatocellular carcinoma compared to deceased donor transplantation. World J Gastroenterol 2014;20:10953-9. DOI PubMed PMC

62. Lin CC, Chen CL. Living donor liver transplantation for hepatocellular carcinoma achieves better outcomes. HepatoBiliary Surg Nutr 2016;5:415-21. DOI PubMed PMC

63. Pomfret EA. Killing two birds with one stone: Antineoplastic immunosuppression. Transplantation 2016;100:14-5. DOI PubMed

64. Rodríguez-Perálvarez M, Tsochatzis E, Naveas MC, et al. Reduced exposure to calcineurin inhibitors early after liver transplantation prevents recurrence of hepatocellular carcinoma. J Hepatol 2013;59:1193-9. DOI PubMed

65. Vivarelli M, Cucchetti A, La Barba G, et al. Liver transplantation for hepatocellular carcinoma under calcineurin inhibitors: reassessment of risk factors for tumor recurrence. Ann Surg 2008;248:857-62. DOI PubMed

66. Menon KV, Hakeem AR, Heaton ND. Meta-analysis: rescurrence and survival following the use of sirolimus in liver transplantation for hepatocellular carcinoma. Aliment Pharmacol Ther 2013;37:411-9. DOI PubMed

67. Cholongitas E, Mamou C, Rodríguez-Castro KI, Burra P. Mammalian target of rapamycin inhibitors are associated with lower rates of hepatocellular carcinoma recurrence after liver transplantation: a systematic review. Transpl Int 2014;27:1039-49. DOI PubMed

68. Geissler EK, Schnitzbauer AA, Zölke C, et al. Sirolimus use in liver transplant recipients with Hepatocellular carcinoma: a randomized, Multicenter, open-label phase 3 Trial. Transplantation 2016;100:116-25. DOI PubMed PMC

69. Bodzin AS, Lunsford KE, Markovic D, Harlander-Locke MP, Busuttil RW, Agopian VG. Predicting mortality in patients developing recurrent hepatocellular carcinoma after liver transplantation: impact of treatment modality and recurrence characteristics. Anna Surg 2017;266:118-25. DOI PubMed

70. Xie DY, Ren ZG, Zhou J, Fan J, Gao Q. 2019 Chinese clinical guidelines for the management of hepatocellular carcinoma: updates and insights. Hepatobiliary Surg Nutr 2020;9:452-63. DOI PubMed PMC

71. Moris D, Shaw BI, McElroy L, Barbas AS. Using hepatocellular carcinoma tumor burden score to stratify prognosis after liver transplantation. Cancers (Basel) 2020;12:1-9. DOI PubMed PMC

72. Mehta N, Heimbach J, Harnois DM, et al. Validation of a risk estimation of tumor recurrence after transplant (RETREAT) score for hepatocellular carcinoma recurrence after liver transplant. JAMA Oncol 2017;3:493-500. DOI PubMed PMC

73. Ho CL, Chen S, Yeung DWC, Cheng TKC. Dual-tracer PET/CT imaging in evaluation of metastatic hepatocellular carcinoma. J Nucl Med 2007;48:902-9. DOI PubMed

74. Cheung TT, Ho CL, Lo CM, et al. 11C-acetate and 18F-FDG PET/CT for clinical staging and selection of patients with hepatocellular carcinoma for liver transplantation on the basis of milan criteria: Surgeon's perspective. J Nucl Med 2013;54:192-200. DOI PubMed

75. Lu RC, She B, Gao WT, et al. Positron-emission tomography for hepatocellular carcinoma: Current status and future prospects. World J Gastroenterol 2019;25:4682-95. DOI PubMed PMC

76. Park JW, Ji HK, Seok KK, et al. A prospective evaluation of 18F-FDG and 11C-acetate PET/CT for detection of primary and metastatic hepatocellular carcinoma. J Nucl Med 2008;49:1912-21. DOI PubMed

77. Niibe Y, Hayakawa K. Oligometastases and oligo-recurrence: the new era of cancer therapy. Jpn J Clin Oncol 2010;40:107-11. DOI PubMed PMC

78. Hellman S, Weichselbaum RR. Oligometastases. J Clin Oncol 1995;13:8-10. DOI PubMed

79. Hwang S, Kim YH, Kim DK, et al. Resection of pulmonary metastases from hepatocellular carcinoma following liver transplantation. World J Surg 2012;36:1592-602. DOI PubMed

80. Xiang ZW, Sun L, Li GH, Maharjan R, Huang JH, Li CX. Progress in the treatment of pulmonary metastases after liver transplantation for hepatocellular carcinoma. World J Hepatol 2015;7:2309-14. DOI PubMed PMC

81. Sahgal A, Larson DA, Chang EL. Stereotactic body radiosurgery for spinal metastases: a critical review. Int J Radiat Oncol Biol Phys 


\section{8;71:652-65. DOI PubMed}

82. Aoki M, Hatayama Y, Kawaguchi H, et al. Stereotactic body radiotherapy for lung metastases as oligo-recurrence: A single institutional study. J Radiat Res 2016;57:55-61. DOI PubMed PMC

83. Ni JY, Liu SS, Xu LF, Sun HL, Chen YT. Meta-analysis of radiofrequency ablation in combination with transarterial chemoembolization for hepatocellular carcinoma. World J Gastroenterol 2013;19:3872-82. DOI PubMed PMC

84. Yuan H, Liu F, Li X, Guan Y, Wang M. Clinical efficacy of chemoembolization with simultaneous radiofrequency ablation for treatment of adrenal metastases from hepatocellular carcinoma. Cancer Imaging 2018;18:24. DOI PubMed PMC

85. Fowler AM, Burda JF, Kim SK. Adrenal artery embolization: Anatomy, indications, and technical considerations. Am J Roentgenol 2013;201:190-201. DOI PubMed

86. Abdelaziz AO, Nabil MM, Abdelmaksoud AH, et al. De-novo versus recurrent hepatocellular carcinoma following direct-acting antiviral therapy for hepatitis C virus. Eur J Gastroenterol Hepatol 2018;30:39-43. DOI PubMed

87. Marangoni G, Faraj W, Sethi H, Rela M, Muiesan P, Heaton N. Liver resection in liver transplant recipients. Hepatobiliary Pancreat Dis Int 2008;7:590-4. PubMed

88. Sommacale D, Dondero F, Sauvanet A, et al. Liver resection in transplanted patients: a single-center Western experience. Transplant Pro 2013;45:2726-8. DOI PubMed

89. Huang J, Yan L, Wu H, Yang J, Liao M, Zeng Y. Is radiofrequency ablation applicable for recurrent hepatocellular carcinoma after liver transplantation? J Surg Res 2015;200:122-30. DOI PubMed

90. Ko HK, Ko GY, Hyun KY, Sung KB. Tumor response to transcatheter arterial chemoembolization in recurrent hepatocellular carcinoma after living donor liver transplantation. Korean J Radiol 2007;8:320-7. DOI PubMed PMC

91. Rammohan A. Embolization of liver tumors: past, present and future. World J Radiol 2012;4:405. DOI PubMed PMC

92. Walton M, Wade R, Claxton L, et al. Selective internal radiation therapies for unresectable early-, intermediate-or advanced-stage hepatocellular carcinoma: Systematic review, network meta-analysis and economic evaluation. Health Technol Assess (Rockv) 2020;24:1-263. DOI PubMed PMC

93. Salem R, Lewandowski RJ, Mulcahy MF, et al. Radioembolization for hepatocellular carcinoma using yttrium-90 microspheres: a comprehensive report of long-term outcomes. Gastroenterology 2010;138:52-64. DOI PubMed

94. Lin HS, Wan RH, Gao LH, Li JF, Shan RF, Shi J. Adjuvant chemotherapy after liver transplantation for hepatocellular carcinoma: a systematic review and a meta-analysis. Hepatobiliary Pancreat Dis Int 2015;14:236-45. DOI PubMed

95. Zhou B, Shan H, Zhu KS, et al. Chemoembolization with Lobaplatin mixed with iodized oil for unresectable recurrent hepatocellular carcinoma after orthotopic liver transplantation. J Vasc Interv Radiol 2010;21:333-8. DOI PubMed

96. Carr BI. Hepatic artery chemoembolization for hepatocellular carcinoma recurrence confined to the transplanted liver. Case Rep Oncol 2012;5:506-10. DOI PubMed PMC

97. Rivera L, Giap H, Miller W, et al. Hepatic intra-arterial infusion of yttrium-90 microspheres in the treatment of recurrent hepatocellular carcinoma after liver transplantation: A case report. World J Gastroenterol 2006;12:5729-32. DOI PubMed PMC

98. Au KP, Chiang CL, Chan ACY, Cheung TT, Lo CM, Chok KSH. Initial experience with stereotactic body radiotherapy for intrahepatic hepatocellular carcinoma recurrence after liver transplantation. World J Clin cases 2020;8:2758-68. DOI PubMed PMC

99. Lee JO, Kim DY, Lim JH, et al. Palliative chemotherapy for patients with recurrent hepatocellular carcinoma after liver transplantation. J Gastroenterol Hepatol 2009;24:800-5. DOI PubMed

100. Lee J, Park JO, Kim WS, et al. Phase II study of doxorubicin and cisplatin in patients with metastatic hepatocellular carcinoma. Cancer Chemother Pharmacol 2004;54:385-90. DOI PubMed

101. Kim HR, Cheon SH, Rha SY, et al. Treatment of recurrent hepatocellular carcinoma after liver transplantation. Asia Pac J Clin Oncol 2011;7:258-69. DOI PubMed

102. Llovet JM, Ricci S, Mazzaferro V, et al. Sorafenib in advanced hepatocellular carcinoma. N Engl J Med 2008;359:378-90. DOI PubMed

103. Yoon DH, Ryoo BY, Ryu MH, et al. Sorafenib for recurrent hepatocellular carcinoma after liver transplantation. Jpn J Clin Oncol 2010;40:768-73. DOI PubMed

104. Galle PR. Sorafenib in advanced hepatocellular carcinoma - we have won a battle not the war. J Hepatol 2008;49:871-3. DOI

105. Bruix J, Qin S, Merle P, et al. Regorafenib for patients with hepatocellular carcinoma who progressed on sorafenib treatment (RESORCE): a randomised, double-blind, placebo-controlled, phase 3 trial. Lancet 2017;389:56-66. DOI PubMed

106. Pelosof L, Lemery S, Casak S, et al. Benefit-risk summary of regorafenib for the treatment of patients with advanced hepatocellular carcinoma that has progressed on sorafenib. Oncologist 2018;23:496-500. DOI PubMed PMC

107. Heo YA, Syed YY. Regorafenib: a review in hepatocellular carcinoma. Drugs 2018;78:951-8. DOI PubMed

108. Finn RS, Merle P, Granito A, et al. Outcomes of sequential treatment with sorafenib followed by regorafenib for HCC: Additional analyses from the phase III RESORCE trial. J Hepatol 2018;69:353-8. DOI PubMed

109. Iavarone M, Invernizzi F, Czauderna C, et al. Preliminary experience on safety of regorafenib after sorafenib failure in recurrent hepatocellular carcinoma after liver transplantation. Am J Transplant 2019;19:3176-84. DOI PubMed

110. Yamashita T, Kudo M, Ikeda K, et al. REFLECT-a phase 3 trial comparing efficacy and safety of lenvatinib to sorafenib for the treatment of unresectable hepatocellular carcinoma: an analysis of Japanese subset. J Gastroenterol 2020;55:113-22. DOI PubMed PMC

111. Reig M, Bruix J. Lenvatinib: can a non-inferiority trial change clinical practice? Lancet 2018;391:1123-4. DOI PubMed

112. Kudo M, Finn RS, Qin S, et al. Lenvatinib versus sorafenib in first-line treatment of patients with unresectable hepatocellular carcinoma: a randomised phase 3 non-inferiority trial. Lancet 2018;391:1163-73. DOI PubMed 
113. Piñero F, Thompson M, Marín JI, Silva M. Lenvatinib as first-line therapy for recurrent hepatocellular carcinoma after liver transplantation: is the current evidence applicable to these patients? World J Transplant 2020;10:297-306. DOI PubMed PMC

114. Lenvatinib following liver transplantation in patients with high-risk hepatocellular carcinoma. ClinicalTrials.gov. Available from: https://clinicaltrials.gov/ct2/show/NCT04168944. [Last accessed on 25 Feb 2021].

115. Abou-Alfa GK, Meyer T, Cheng AL, et al. Cabozantinib in patients with advanced and progressing hepatocellular carcinoma. $N$ Engl $J$ Med 2018;379:54-63. DOI PubMed PMC

116. Allaire M, Nault JC. Cabozantinib and the moving field of systemic treatments in advanced hepatocellular carcinoma. HepatoBiliary Surg Nutr 2019;8:53-5. DOI PubMed PMC

117. Personeni N, Rimassa L, Pressiani T, Smiroldo V, Santoro A. Cabozantinib for the treatment of hepatocellular carcinoma. Expert Rev Anticancer Ther 2019;19:847-55. DOI PubMed

118. Cabozantinib to treat recurrent liver cancer post transplant. Clinicaltrials.gov. Available from: https://clinicaltrials.gov/ct2/show/NCT04204850. [Last accessed on 25 Feb 2021].

119. Tagliamonte M, Petrizzo A, Tornesello ML, Ciliberto G, Buonaguro FM, Buonaguro L. Combinatorial immunotherapy strategies for hepatocellular carcinoma. Curr Opin Immunol 2016;39:103-13. DOI PubMed

120. Prieto J, Melero I, Sangro B. Immunological landscape and immunotherapy of hepatocellular carcinoma. Nat Rev Gastroenterol Hepatol 2015;12:681-700. DOI PubMed

121. Ringelhan M, Pfister D, O'Connor T, Pikarsky E, Heikenwalder M. The immunology of hepatocellular carcinoma review-article. Nat Immunol 2018;19:222-32. DOI

122. Tsuchiya N, Sawada Y, Endo I, Uemura Y, Nakatsura T. Potentiality of immunotherapy against hepatocellular carcinoma. World $J$ Gastroenterol 2015;21:10314-26. DOI PubMed PMC

123. Rammohan A. Pembrolizumab for advanced hepatocellular carcinoma: tunnel at the end of the light. Dig Med Res 2018;1:10. DOI

124. Varkaris A, Lewis DW, Nugent FW. Preserved liver transplant after pd-1 pathway inhibitor for hepatocellular carcinoma. Am J Gastroenterol 2017;112:1895-6. DOI PubMed

125. Rammohan A, Reddy MS, Farouk M, Vargese J, Rela M. Pembrolizumab for metastatic hepatocellular carcinoma following live donor liver transplantation: the silver bullet? Hepatology 2018;67:1166-8. DOI PubMed

126. Zhu AX, Finn RS, Edeline J, et al. Pembrolizumab in patients with advanced hepatocellular carcinoma previously treated with sorafenib (KEYNOTE-224): a non-randomised, open-label phase 2 trial. Lancet Oncol 2018;19:940-52. DOI PubMed

127. El-Khoueiry AB, Sangro B, Yau T, et al. Nivolumab in patients with advanced hepatocellular carcinoma (CheckMate 040): an openlabel, non-comparative, phase 1/2 dose escalation and expansion trial. Lancet 2017;389:2492-502. DOI PubMed PMC

128. De Martin E, Michot JM, Rosmorduc O, Guettier C, Samuel D. Liver toxicity as a limiting factor to the increasing use of immune checkpoint inhibitors. JHEP Rep 2020;2:100170. DOI PubMed PMC

129. Wu Z, Lai L, Li M, Zhang L, Zhang W. Acute liver failure caused by pembrolizumab in a patient with pulmonary metastatic liver cancer. Medicine (Baltimore) 2017;96:e9431. DOI PubMed PMC

130. Al Jarroudi O, Ulusakarya A, Almohamad W, Afqir S, Morere JF. Anti-programmed cell death protein 1 (pd-1) immunotherapy for metastatic hepatocellular carcinoma after liver transplantation: a report of three cases. Cureus 2020;12:e11150. DOI PubMed PMC 